similarity with those of the eastern Spanish palæolithic art, where also is found a twisted perspective in depicting horns of stags and oxen, which appears at Lescaux. From this and other comparisons, the important inference is drawn that the paintings of Lescaux are earlier than both Magdalenian and Solutrean, but later than typical Aurignacian. They represent the phase of Upper Palæolithic culture, but recently differentiated and known as "Perigordian".

\section{Prof. Ernest O. Lawrence: Duddell Medallist}

THE formal presentation of the seventeenth Duddell Medal of the Physical Society to Prof. E. O. Lawrence, the award of which was announced in NATuRE of June 1, p. 852, was made at a dinner of the American Physical Society in Philadelphia on December 27 by Mr. Neville Butler, First Counsellor to the British Embassy and H.M. Chargé d'Affaires ad interim in Washington-it had been the late Lord Lothian's intention to present the medal. At a luncheon held by the Physical Society in London on the same day, an interesting word picture of Prof. Lawrence was given by his friend and former pupil, Dr. W. B. Mann. Dr. Mann first referred briefly to the development of the Berkeley cyclotrons, from the 4 -inch instrument in 1930 (when Lawrence, at the age of twenty-nine, had recently been appointed professor of physics in the University of California), to the 37 -inch (85-ton) and 60-inch (220ton) cyclotrons and the projected giant cyclotron of some 4,900 tons. He then described the team work of the Radiation laboratory at Berkeley and recalled many incidents to show the outstanding qualities of its distinguished chief-his deep, innate sense of physics, his skill in finding the causes of breakdowns, his large share in making the subsequent readjustments until perfect running was again effected, his boisterous and irrepressible enthusiasm away from work (such as on a ski-trip or in his motor-cruiser on San Francisco Bay), and his complete selflessness. Prof. Birge had quoted Lawrence's first remark on being informed of the award to him of the Nobel Prize for Physics in 1939: "It goes without saying that it is the laboratory that is honoured, and I share the honours with my co-workers past and present." Again, the closing words of Lawrence's response at the presentation of that Prize were: "May I again give expression to a profound feeling of gratitude and appreciation for this great honour, which I share with the university and with all those outside who have contributed to make our work possible and, above all, with my valued colleagues and co-workers both past and present." An article based upon Dr. Mann's address appears in the January issue of the Proceedings of the Physical Society.

\section{New Cyclotron at Berkeley, California}

GooD progress is being made, according to news received recently from the United States, in the erection of the 184-inch cyclotron at Berkeley, California. The cost of this apparatus, it will be recalled (Nature, May 18, 1940 , p. 776), will be more than $£ 200,000$, and is being provided by the Rockefeller Institute. The concrete bed for the steel magnet, containing 1,200 tons of concrete, is finished. The erection of the steelwork is now starting, and is expected to be completed by April next. This will contain 3,700 tons of steel, the overall dimensions being, length 56 feet, width 184 inches, height 30 feet. The upper and lower yokes are to be built of some 36 sheets each of steel, 2 inches thick and 5.6 feet long, bolted and ultimately to be welded together to withstand earthquake shock. 300 tons of copper in the form of strip, 4 inches wide and $\frac{1}{1}$ inch thick, will be required for the windings. The cyclotron is expected to yield one hundred million electron-volt deuterons in a field of 10 kilogauss, for which the resonance wave-length is 39 metres:

\section{Physiology at Cambridge: Mr. W. Freeman}

AT a meeting of the Physiological Society held in Cambridge on December 18, a presentation was made by physiologists trained in the Cambridge school to Mr. William Freeman, the senior laboratory assistant. Mr. Freeman, known to many generations of students as 'John', completed his fiftieth year in the laboratory last October. As biological technician he was closely associated with Langley and Anderson in their work on the autonomic system, but during the past fifty years he has aided no less than four of the secretaries of the Royal Society (Michael Foster, Sir William Hardy, Sir Henry Dale and Prof. A. V. Hill) and three of its presidents (Sir Charles Sherrington, Sir Frederick Gowland Hopkins and Sir Henry Dale). The presentation was made by Sir Henry Dale after congratulatory speeches by Prof. E. D. Adrian and Dr. L. E. Shore. 